\title{
Novel Wideband Metallic Patch Antennas with Low Profile
}

\author{
Zhong-Xiang Zhang, ${ }^{1,2}$ Meng Kong, ${ }^{1}$ Shuo Wang, ${ }^{2}$ and Yong-Mei Pan ${ }^{3}$ \\ ${ }^{1}$ School of Electronic and Information Engineering, Hefei Normal University, Hefei 230601, China \\ ${ }^{2}$ Key Laboratory of Polarization Imaging Detection Technology in Anhui Province, Hefei 230031, China \\ ${ }^{3}$ School of Electronic and Information Engineering, South China University of Technology, Guangzhou 510641, China \\ Correspondence should be addressed to Zhong-Xiang Zhang; zhzhx@mail.ustc.edu.cn
}

Received 7 December 2016; Revised 18 January 2017; Accepted 27 March 2017; Published 30 April 2017

Academic Editor: Rodolfo Araneo

Copyright (C) 2017 Zhong-Xiang Zhang et al. This is an open access article distributed under the Creative Commons Attribution License, which permits unrestricted use, distribution, and reproduction in any medium, provided the original work is properly cited.

Two planar metallic patch (MP) antennas with low profiles are investigated and compared in this paper. The MP of each antenna consists of metallic patch cells and it is centrally fed by a rectangular slot. Two modes with close resonance frequencies are excited, providing a quite wide bandwidth. The antenna principle is explained clearly through a parametric study. Simulated and measured results show that the MP antennas with profile of $0.06 \lambda_{0}$ can obtain a $10 \mathrm{~dB}$ impedance bandwidth of $\sim 32 \%$ and an average gain of $\sim 10 \mathrm{dBi}$.

\section{Introduction}

Microstrip patch antenna attracts increasing interest in the wireless communication systems with low profile, low cost, and ease of fabrication and installation. Nevertheless, it is repulsive for the narrow impedance bandwidth. In fact, the bandwidth has been enhanced to about $10 \%$ with thick substrate [1], about $30 \%$ with U-slot on the patch [2, 3], about $35 \%$ with L-shaped feeding probe [4-6], and about $40 \%$ with stacked patches [7]. In the past few decades, metamaterials have been attractive to a wide range of electromagnetic applications due to their very unique properties. Various metasurfaces based antennas have been proposed and investigated for performance enhancement and size miniaturization [8-11]. The attempt of designing a broadband and directive metamaterial-inspired antenna has been reported [12]. It has demonstrated a bandwidth of $36 \%$ with a $2 \times 2$ mushroom structure and with an elliptical ring slot on the surface.

Recently, a metamaterial-based broadband $4 \times 4$ mushroom antenna has been presented in [13]. The mushroom unit cell consists of a square patch and a shorting via. The shorting via is positioned at the center of the square patch and it connects the patch to the ground plane. Fed by a microstrip-coupled slot, two resonant modes on the righthanded region of the metasurface mushroom structure can be excited and the antenna with a thickness of $0.06 \lambda_{0}$ achieves an impedance bandwidth of $25 \%$ and an average gain of 9.9- $\mathrm{dBi}$. In this paper, the shorting vias are removed and MPs consisting of simple rectangular patch cells are used instead above a rectangular slot. It is found that the antenna performances are comparable to those of the antenna having vias [13]. A 32\% impedance bandwidth and a $10-\mathrm{dBi}$ average gain can be obtained. This is very desirable since the fabrication process is greatly simplified and the cost reduces accordingly. To demonstrate the idea, two wideband MP antennas operating at $5 \mathrm{GHz}$ were designed. For each antenna, the reflection coefficient, radiation pattern, and antenna gain were simulated and measured, with reasonable agreement obtained.

\section{Antenna Configuration}

Three antennas using different MPs are studied and compared in this section. Figure 1(a) shows configuration of the reference $4 \times 4$ mushroom MP I [13], which is fabricated on a substrate having thickness $h_{1}=3 \mathrm{~mm}$ and relative permittivity $\varepsilon_{r 1}=2.2$. Each mushroom cell consists of a rectangular patch and a shorting via. The via is located at the center of the patch, connecting the patch to the background plane. The diameter of the shorting via, the length, and width of the patch are $d, l$, and $w$, respectively. The $4 \times 4$ mushroom cells are evenly distributed along $x$ - and $y$-axes, 


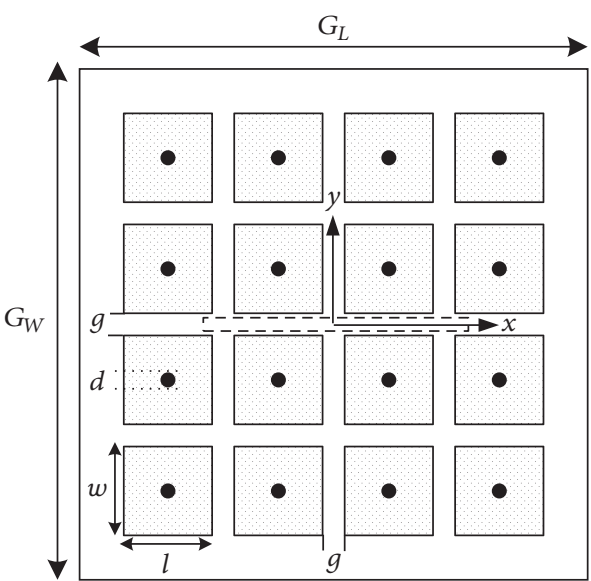

(a)

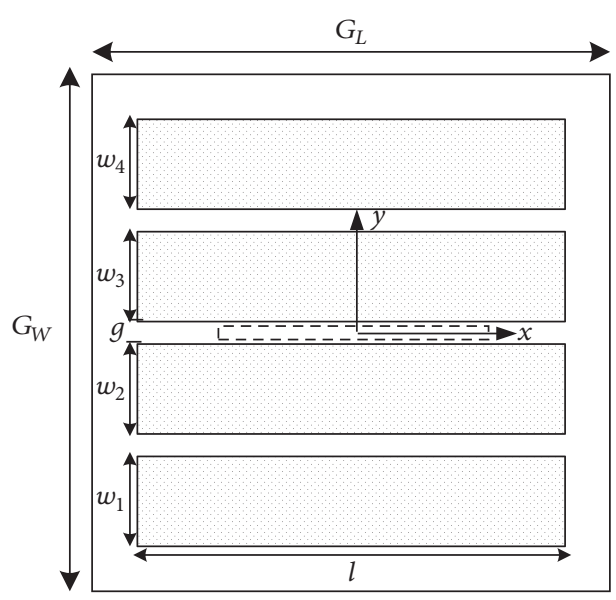

(c)

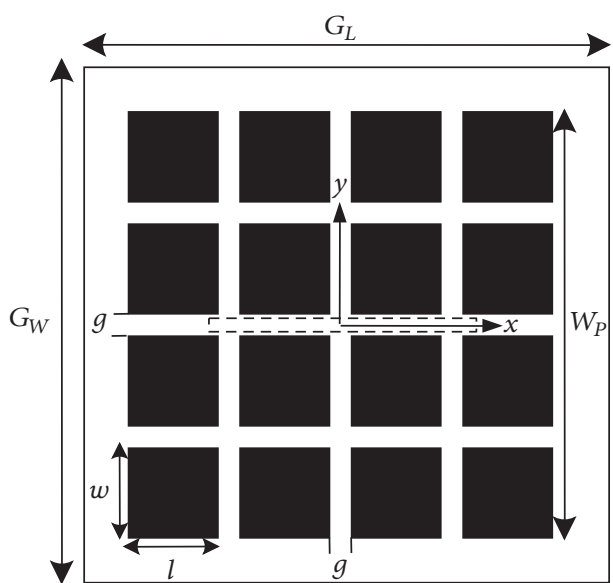

(b)

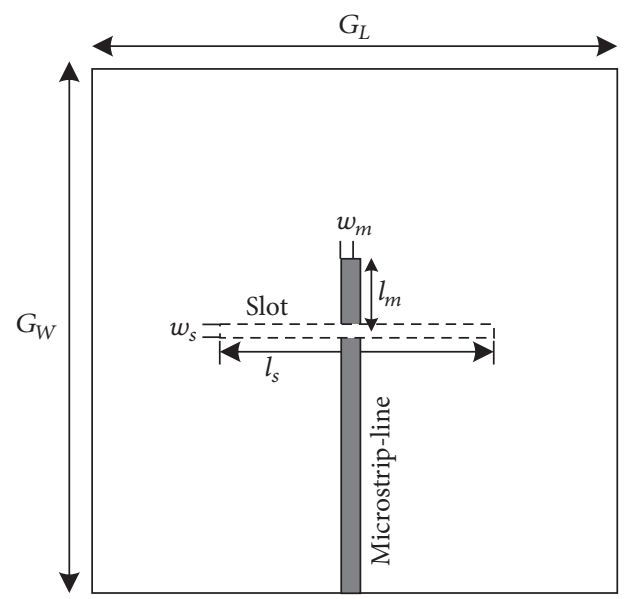

(d)

FIGURE 1: Three slot-fed antennas with different MPs. (a) MP I composed of $4 \times 4$ rectangular patch cells which are shorted to the ground plane with vias. (b) MP II composed of $4 \times 4$ rectangular patch cells. (c) MP III composed of $1 \times 4$ rectangular patch cells. (d) Microstrip-coupled slot.

with the gap width between two adjacent units given by $g$. Figure 1(b) shows a new MP of antenna II, which has similar configuration with MP I except that all shorting vias are removed. Based on MP II, another simpler MP III is proposed and shown in Figure 1(c). In this case, the gaps between the patch cells along $x$-axis are eliminated and the MP turns into a $1 \times 4$ rectangular patch array. All three MPs are fed at the center by a microstrip-coupled slot, which is fabricated on a substrate with thickness $h_{2}=0.813 \mathrm{~mm}$ and relative permittivity $\varepsilon_{r 2}=3.38$. As shown in Figure $1(\mathrm{~d})$, the slot having length $l_{s}$ and width $w_{s}$ was cut at the top surface, and a $50 \Omega$ microstrip feed-line with a width of $w_{m}$ and a stub length of $l_{m}$ was fabricated on the other side of the substrate.

For comparison, three antennas using different MPs were designed to operate at the same frequency of $5 \mathrm{GHz}$. In each case, the slot length $l_{s}$ and microstrip stub length $l_{m}$ were tuned to optimize the impedance match. Figures 2(a) and 2(b) show the simulated reflection coefficients and antenna gains, respectively. It can be seen from Figure 2(a) that reference antenna I has a $-10 \mathrm{~dB}$ impedance bandwidth $\left(\left|\mathrm{S}_{11}\right|<\right.$ $-10 \mathrm{~dB})$ of $22.1 \%(4.42-5.52 \mathrm{GHz})$, comparable to $25 \%$ of the design in [13]. The $\mathrm{TM}_{10}$ and antiphase $\mathrm{TM}_{20}$ modes of the mushroom structure are simultaneously excited to provide such a broadband operation. As for antennas II and III, also two modes exist in the passbands, but their resonance frequencies move farther away from each other, leading to even wider bandwidths of $29.9 \%(4.21-5.69 \mathrm{GHz})$ and $32.1 \%$ (4.16-5.75 GHz).

With reference to Figure 2(b), the three antennas have almost the same gain level. An average gain of near $11 \mathrm{dBi}$ is obtained for each antenna in its corresponding impedance passband. Table 1 summarizes the antenna dimensions, bandwidths, and gains for the three cases. It was found that antenna I has the largest area of $0.88 \lambda_{0}{ }^{2}$, which is $10.1 \%$ larger than antenna III and $26.8 \%$ larger than antenna II. Figure 3 depicts the simulated surface current distributions on the three MPs at $5 \mathrm{GHz}$. As can be observed from the figure, the distribution patterns of the three cases are very similar with each other, especially for MP II and III.

Based on the comparison, it can be concluded that instead of increasing the complexity of structure, the introduction of shorting vias shows no advantage in improving antenna 


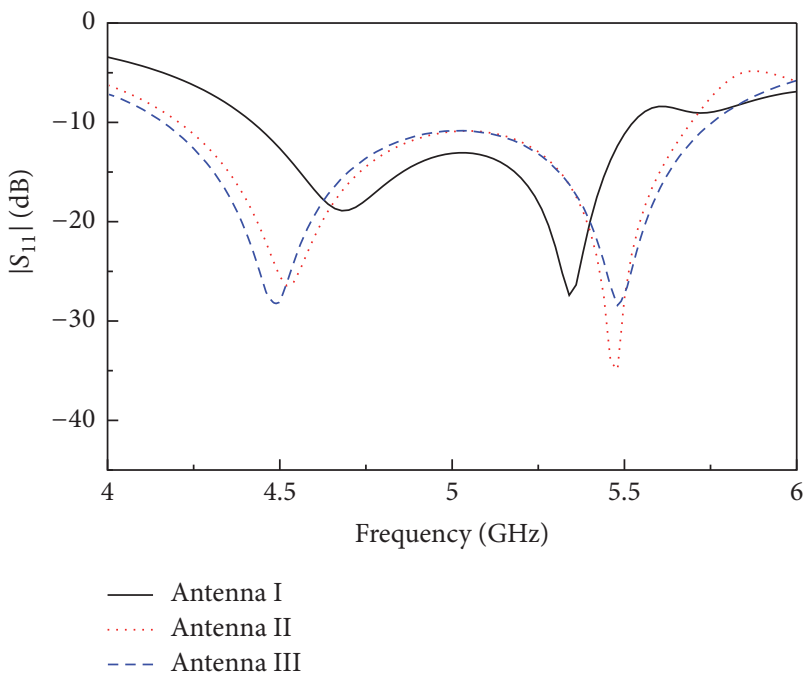

(a)

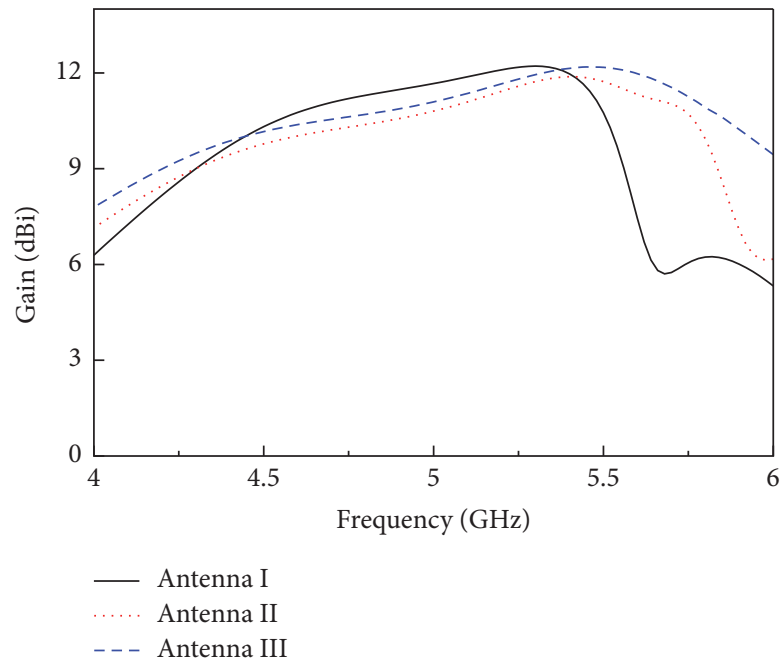

(b)

FIGURE 2: Simulated reflection coefficients and gains of the three slot-fed antennas with different MPs. (a) Reflection coefficients. (b) Antenna gains.

TABLE 1: Antenna dimensions, bandwidths, and average gains of antennas.

\begin{tabular}{|c|c|c|c|c|c|}
\hline Antenna & $\begin{array}{c}\text { Cell size } \\
w \times l \times g(\mathrm{~mm})\end{array}$ & $\begin{array}{c}\text { Slot size } \\
l_{s} \times w_{s}(\mathrm{~mm})\end{array}$ & $\begin{array}{l}\text { Stub length } \\
l_{m}(\mathrm{~mm})\end{array}$ & $\begin{array}{l}\text { Impedance } \\
\text { bandwidth }\end{array}$ & $\begin{array}{c}\text { Average gain } \\
(\mathrm{dBi})\end{array}$ \\
\hline I & $13.3 \times 13.3 \times 1$ & $33 \times 2$ & 10 & $22.1 \%$ & 11.4 \\
\hline II & $12.1 \times 12.1 \times 0.5$ & $30 \times 2$ & 10 & $29.9 \%$ & 10.6 \\
\hline III & $12.1 \times 56 \times 0.5$ & $32 \times 2$ & 10 & $32.1 \%$ & 10.9 \\
\hline
\end{tabular}

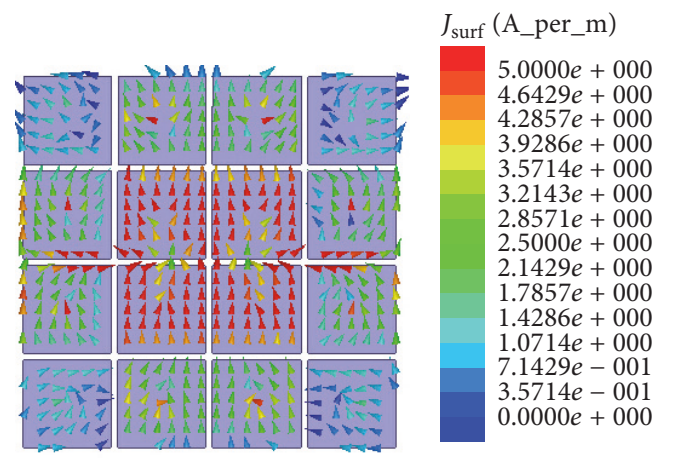

(a)

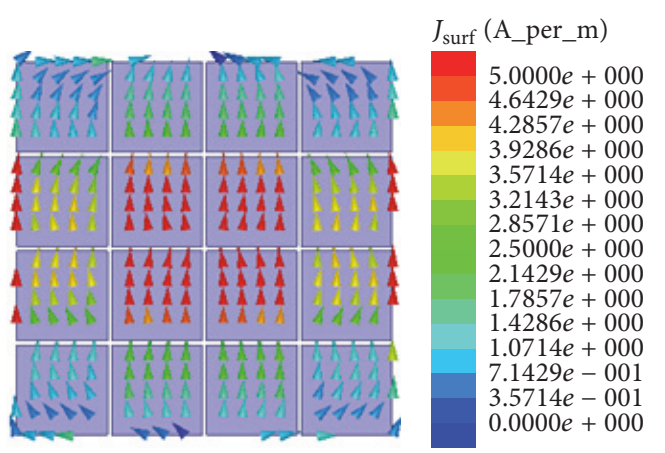

(b)

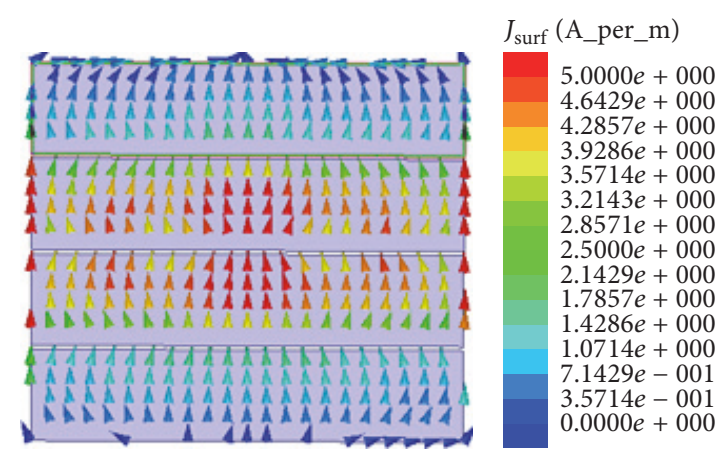

(c)

FIgURE 3: Simulated surface current distributions on MPs at 5 GHz. (a) MP I. (b) MP II. (c) MP III. 


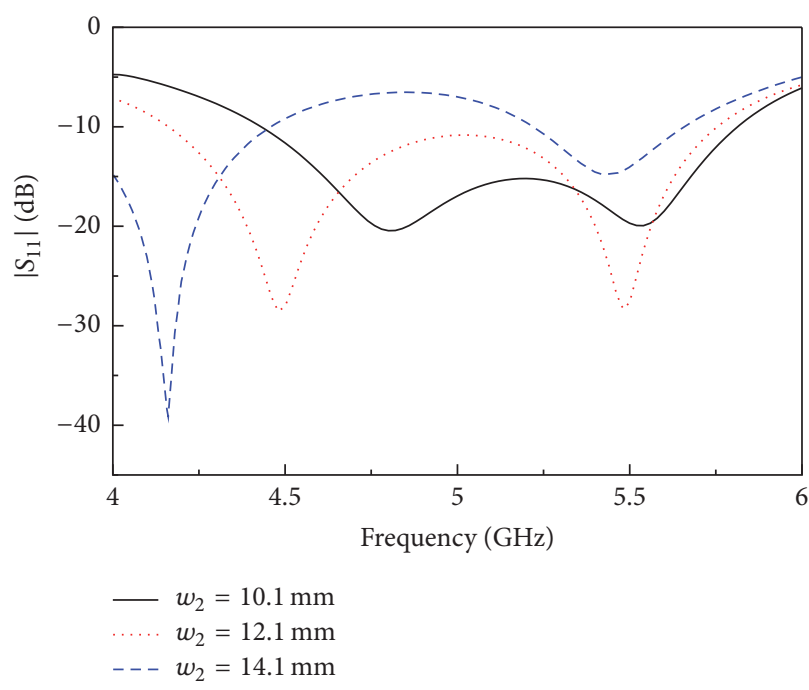

(a)

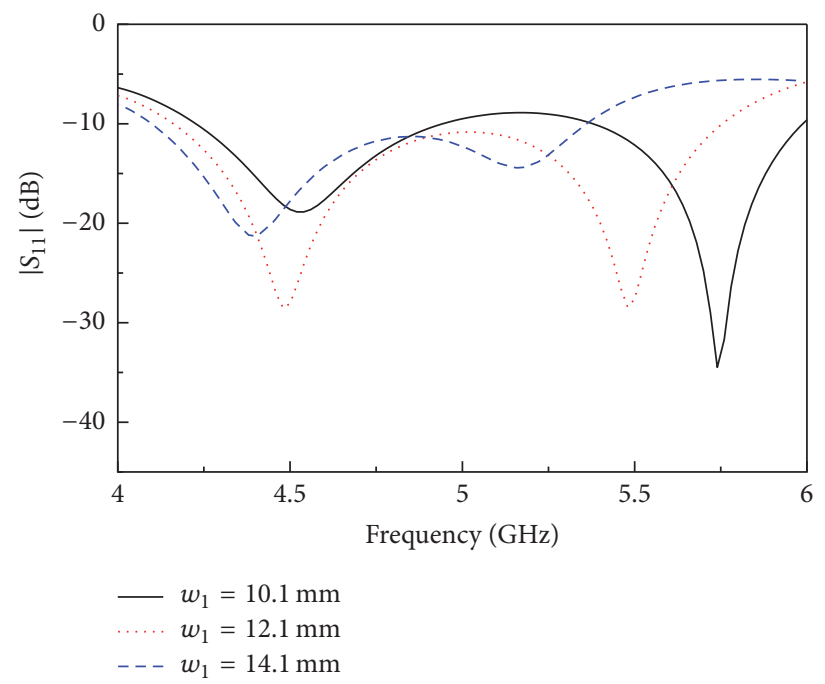

(b)

FIGURE 4: Simulated reflection coefficients of antenna III as a function of frequency for different cell widths. (a) $w_{1}=w_{4}=12.1 \mathrm{~mm}$, $w_{2}=w_{3}=w$. (b) $w_{2}=w_{3}=12.1 \mathrm{~mm}, w_{1}=w_{4}=w$.

performance. Therefore, MPs II and III are superior to MP I in the design of a wideband antenna. On the other hand, the similar performances and current distributions of MPs II and III verify that their operating principles should be the same, and the gaps along $x$-axis can be eliminated without affecting antenna performances at all.

\section{Simulated and Measured Results}

3.1. Parametric Study. The geometry of the slot-fed MP antennas is illustrated in Figure 1. The MP unit cell consists of a square patch with a side width $w$, and the MP cells are two-dimensionally distributed with a gap width $g$ in between on the center of the dielectric substrate. When the height of the substrate $h$ is very small compared with the wavelength $\lambda_{0}$, a transmission-line model can be utilized to analyze the proposed MP antenna. Due to the fringing field at the open edges of the MP array, the MP array cavity is assumed to have an additional extended length at each end. Since the gap width $g$ is much smaller than the MP cells period, the extended length $\Delta L$ can be approximated to that of the corresponding entire rectangular patch with the same width of $W_{P}$, and it is given by [14]

$$
\begin{aligned}
& \frac{\Delta L}{h}=0.412 \frac{\left(\varepsilon_{\text {reff }}+0.3\right)\left(W_{p} / h+0.262\right)}{\left(\varepsilon_{\text {reff }}-0.258\right)\left(W_{p} / h+0.813\right)}, \\
& \varepsilon_{\text {reff }}=\frac{\varepsilon_{r}+1}{2}+\frac{\varepsilon_{r}-1}{2}\left(1+12 \frac{h}{W_{P}}\right)^{-1 / 2}, \\
& W_{P}=4 w+3 g .
\end{aligned}
$$

To characterize the designs, parametric studies of antennas II and III have been carried out using HFSS. Similar phenomena have been observed, and therefore only the results of simpler MP antenna III are shown here for brevity.
Figure 4 shows the reflection coefficients as a function of frequency for different patch cell widths. Two different cases have been studied: (a) the widths of $w_{1}$ and $w_{4}$ are fixed at $12.1 \mathrm{~mm}$, but $w_{2}=w_{3}=w$ varies from 10.1 to $14.1 \mathrm{~mm}$; (b) the widths of $w_{2}$ and $w_{3}$ are fixed at $12.1 \mathrm{~mm}$, but $w_{1}=$ $w_{4}=w$ varies from 10.1 to $14.1 \mathrm{~mm}$. In each case, $w_{1}$ and $w_{4}, w_{2}$ and $w_{3}$ are set equal to each other to provide a symmetrical antenna structure and thus symmetrical radiation patterns. With reference to Figure 4(a), when only $w_{2}$ and $w_{3}$ increase from 10.1 to $14.1 \mathrm{~mm}$, the upper resonance frequency at $\sim 5.5 \mathrm{GHz}$ remains unchanged, but the lower resonance frequency decreases from 4.8 to $4.16 \mathrm{GHz}$, showing that the lower mode is generated by the pair of patches 2, 3 which are right above the feeding slot. The situation is reversed in case (b). As shown in Figure 4(b), the resonance frequency is more sensitive to $w_{1}$ and $w_{4}$ in the upper band than for the lower band, indicating that the upper band is associated with the pair of patches 1,4 .

The surface current distribution of MP III at the two resonance frequencies 4.5 and $5.5 \mathrm{GHz}$ is shown in Figure 5. It can be seen that the currents are concentrated mainly on patches 2 and 3 at lower $4.5 \mathrm{GHz}$ whereas they are concentrated mainly on patches 1 and 4 at upper $5.5 \mathrm{GHz}$, verifying the above conclusion. These results demonstrate that MP III behaves like a gap-coupled parasitic patch antenna, which consists of several patch resonators coupled together by capacitive radiating-edge gaps $[15,16]$. At one frequency, one of the patch resonators is resonant and at nearby frequency other resonators become resonant. The multiple resonances yield a wide bandwidth. The difference is that in probe-fed parasitic patch antenna $[15,16]$, driven patch and parasitic elements should have slightly different resonant lengths to provide close resonance frequencies. However, for the slot-fed MP III, identical patch cells can be used and the two close resonance frequencies are obtained by the different loading effects of the feeding slot on the patches. Also, it is worth 


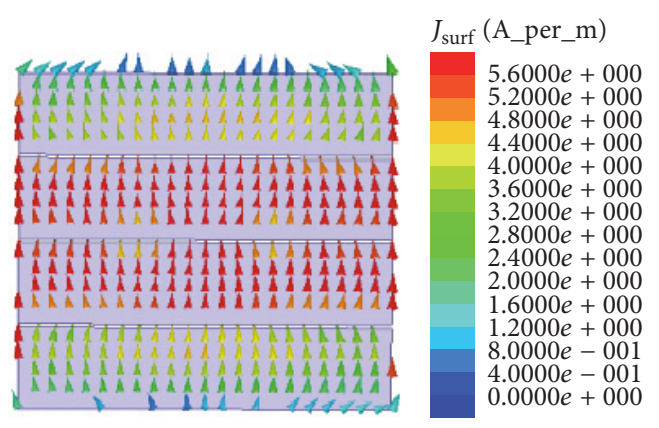

(a)

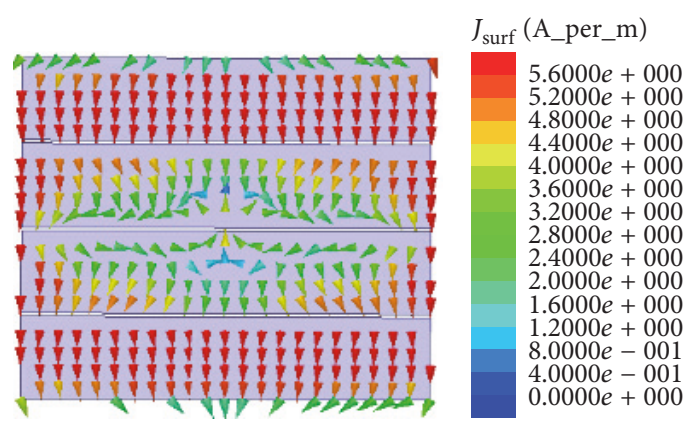

(b)

FIGURE 5: Simulated surface current distribution on MP III at resonance frequencies. (a) $4.5 \mathrm{GHz}$. (b) $5.5 \mathrm{GHz}$.

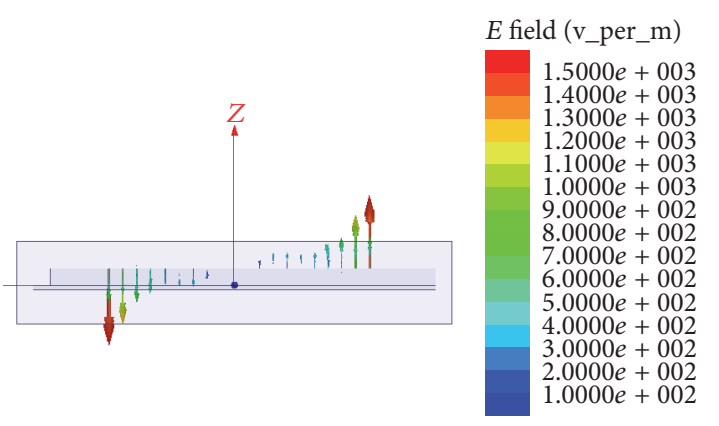

(a)

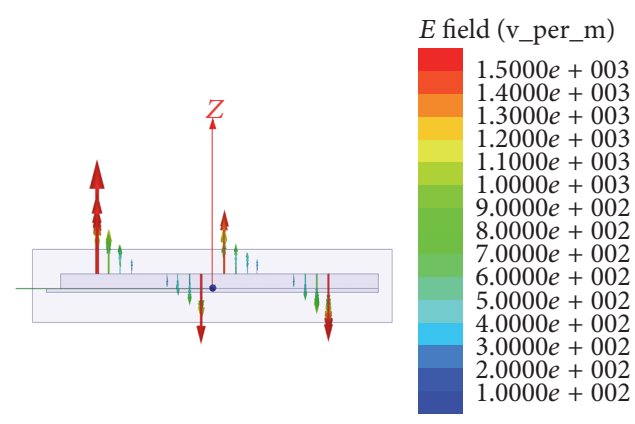

(b)

Figure 6: Simulated $E$-filed distribution on $y=0 \mathrm{~mm}$ planes of MP II at resonance frequencies. (a) $4.5 \mathrm{GHz}$. (b) $5.5 \mathrm{GHz}$.

mentioning that compared with the probe-fed parasitic patch antennas, the proposed slot-fed MP III provides much wider bandwidth, higher gain, and more stable and symmetrical radiation patterns.

The simulated filed distribution of MP II at the two resonance frequencies 4.5 and $5.5 \mathrm{GHz}$ is shown in Figure 6. It can be seen that the $E$-filed distribution of the $4 \times 4 \mathrm{MP}$ cell array at $4.5 \mathrm{GHz}$ is similar to the $\mathrm{TM}_{10}$ mode of a conventional patch antenna except the radiation from the gaps between MP cells shown in Figure 6(a). And the $E$-filed distribution of the $4 \times 4 \mathrm{MP}$ cell array at $5.5 \mathrm{GHz}$ is similar to the antiphase $\mathrm{TM}_{20}$ mode shown in Figure 6(b). In the MP structure, the ratio of the antiphase $\mathrm{TM}_{20}$ mode resonant frequency to the $\mathrm{TM}_{10}$ mode resonant frequency can be much less than two. Therefore, the smaller ratio of the antiphase $\mathrm{TM}_{20}$ mode resonant frequency to the $\mathrm{TM}_{10}$ mode, together with the reduced quality factor with the cell gaps, leads to broadband operation of the MP antenna.

Figure 7 shows the reflection coefficients for different cell lengths $l$. As can be seen from the figure, the reflection coefficient varies very slightly when $l$ is increased significantly from 46 to $56 \mathrm{~mm}$, and good match is maintained across the impedance passband. This is because $l$ corresponds to the dimension of nonradiating edge of the patch. Also due to this reason, the antenna performances of MP II and III are similar to each other regardless of having gaps along the nonradiating edge or not. However, there is a sharp change point at $4.28 \mathrm{GHz}$ for $l=51 \mathrm{~mm}$ and $4.75 \mathrm{GHz}$ for $l=$ $46 \mathrm{~mm}$ in the passband. This should be caused by the weak

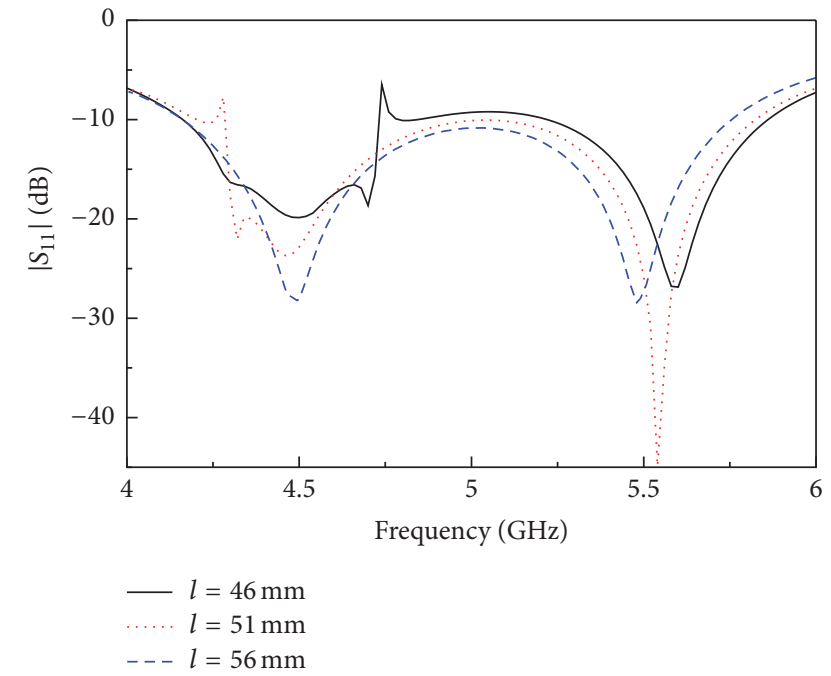

FIGURE 7: Simulated reflection coefficients of antenna III as a function of frequency for different cell lengths of $l=46,51$ and $56 \mathrm{~mm}$.

resonance along the nonradiating edge, since the length and frequency satisfy the relation of $l=\lambda_{e}=c / f_{o} \sqrt{\varepsilon_{e}}$, where $\lambda_{e}$ is the guide wavelength, and $\varepsilon_{e}$ is the effective dielectric constant of the microstrip line given by $\varepsilon_{e}=\left(\varepsilon_{r}+1\right) / 2+$ $\left(\varepsilon_{r}+1\right) / 2 \sqrt{1+12 h / w}$ [17]. Although the weak resonance affects the refection coefficient insignificantly, it decreases the 


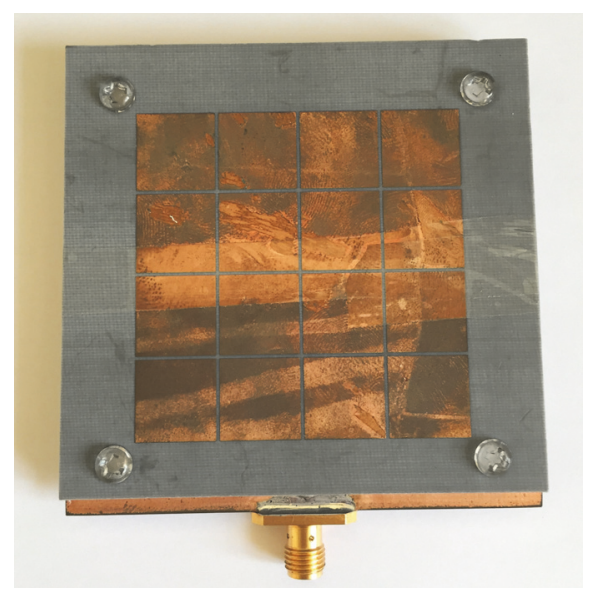

(a)

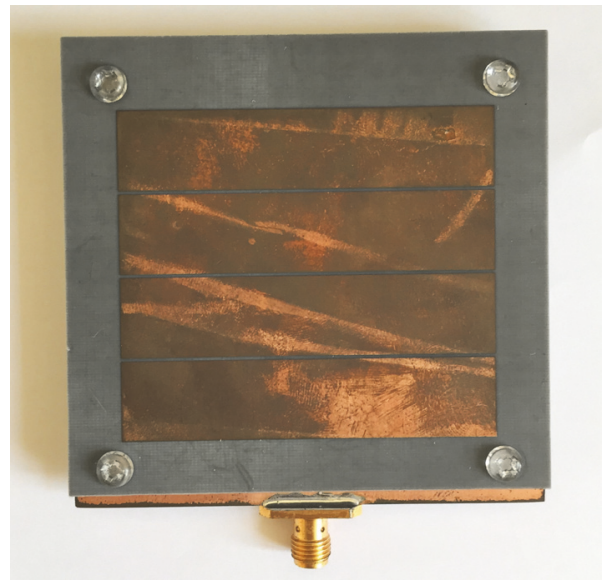

(b)

Figure 8: Photo of two planar MP antennas. (a) MP II composed of $4 \times 4$ rectangular patch cells. (b) MP III composed of $1 \times 4$ rectangular patch cells.

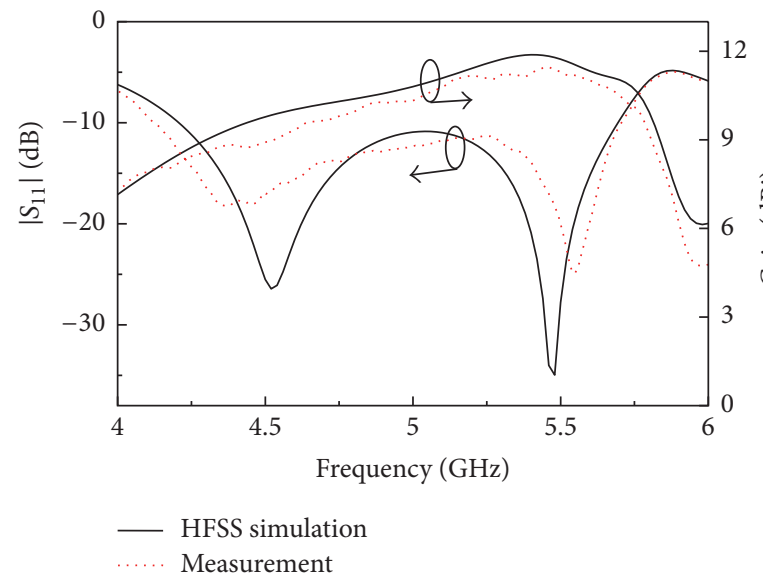

(a)

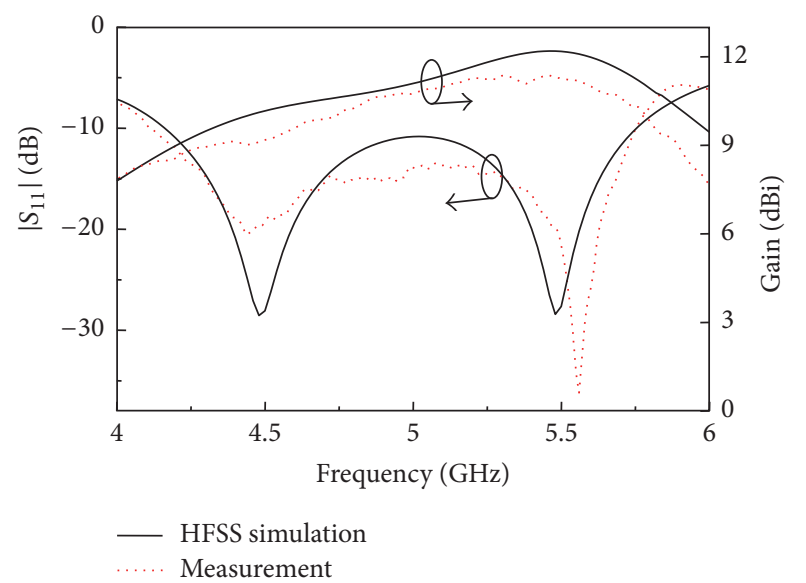

(b)

FIgUre 9: Measured, simulated reflection coefficients and gains of antennas II and III. (a) Antenna II. (b) Antenna III.

antenna gain by $\sim 1 \mathrm{~dB}$ at that frequency. Therefore, a larger $l$ of $56 \mathrm{~mm}$ is preferable to exclude the resonance outside the useable passband. It is worth mentioning that since the length is divided into 4 subsections in MP II, the resonance condition is destroyed; then smaller total length can be used without weak resonance happening. This is the reason why the size of MP II is a bit smaller than that of MP III, as shown in Table 1.

Finally, the effects of feeding slot are investigated. It is found that the variations of parameters $w_{s}, l_{s}$, and $l_{m}$ mainly affect the match level but not the resonance frequency. Therefore, they can be tuned for a good match. Since the results are similar with those in [13], they are not included in this paper for brevity.

3.2. Measurement Verification. To verify the designs, two prototypes of antenna II and III were fabricated (shown in Figure 8) and tested. In this paper, the reflection coefficient was measured using an HP8510C network analyzer, whereas other measured results were obtained using a Satimo Starlab System. Figures 9(a) and 9(b) show the measured, simulated reflection coefficients and gains of antennas II and III, respectively. Reasonable agreement between the simulated and measured results is observed, with the discrepancy caused by experimental tolerances and imperfections including the inevitable airgap between the two substrates. With reference to the figure, the measured bandwidths of the two antennas are almost the same, given by $32.2 \%(4.12-5.70 \mathrm{GHz})$ and $33.3 \%(4.11-5.75 \mathrm{GHz})$ for antennas II and III, respectively. Also, similar gain levels have been observed for the two antennas. Take antenna III for an example, the antenna gain varies between 8.4 and $11.4 \mathrm{dBi}$ across the impedance passband. The average antenna gain is $10.2 \mathrm{dBi}$, which is close to $9.9 \mathrm{dBi}$ in [13]. Figure 10 shows the measured and simulated field pattern at $5 \mathrm{GHz}$. Broadside radiation patterns are observed as expected, with maximum radiation pointing to the boresight direction $\left(\theta=0^{\circ}\right)$. The copolarized fields in the boresight direction of both antennas are stronger than 


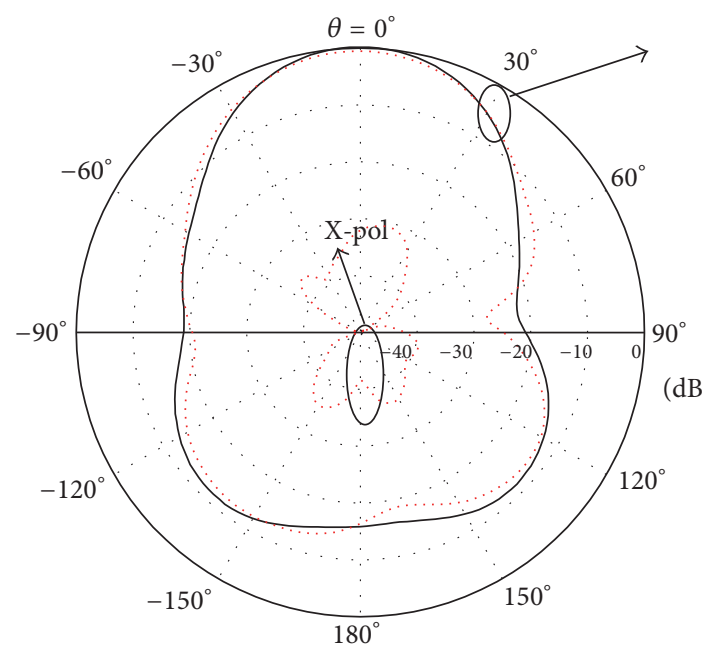

$\left(\phi=0^{\circ}\right)$

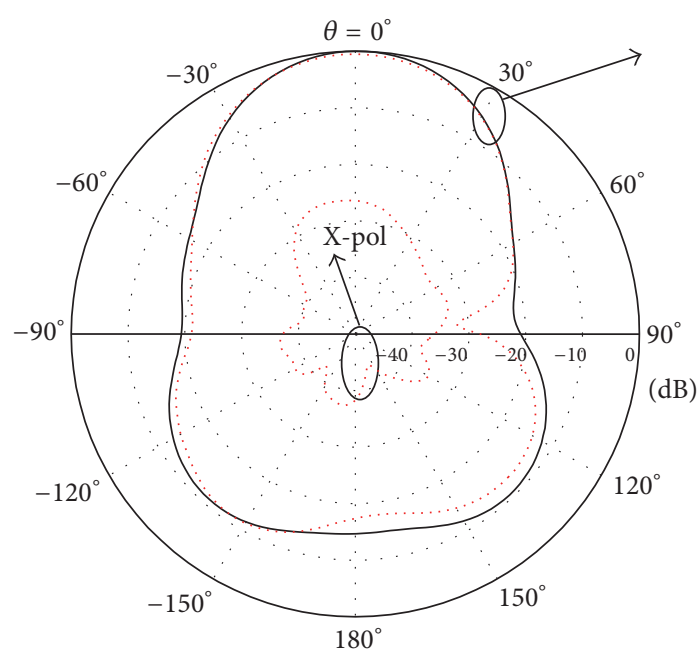

$\left(\phi=0^{\circ}\right)$

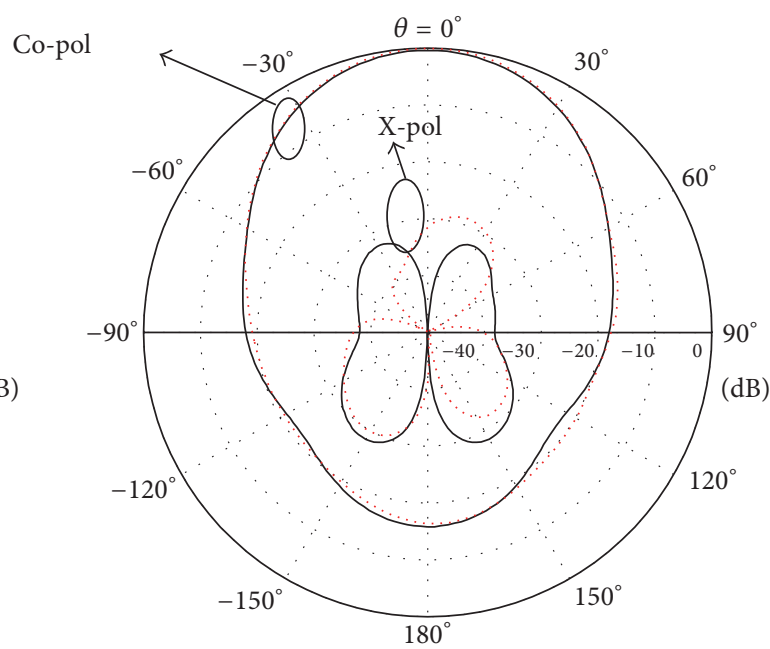

$\left(\phi=90^{\circ}\right)$

(a)

Co-pol

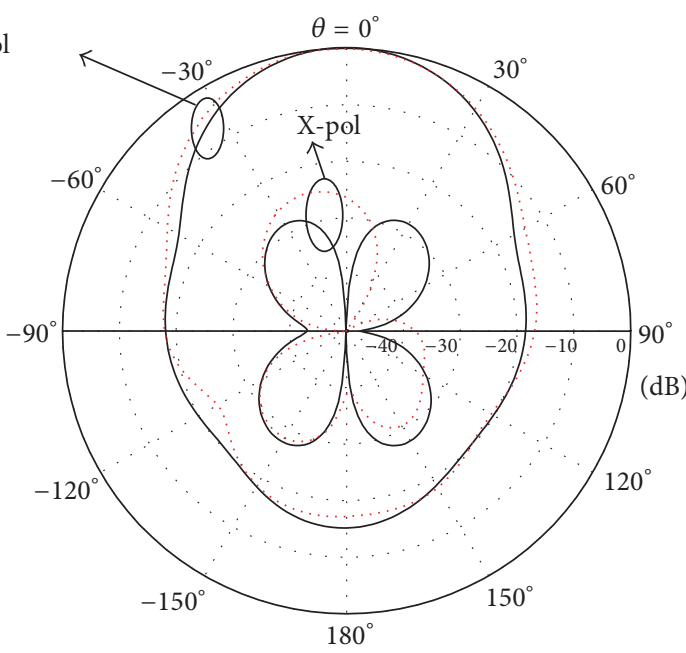

$\left(\phi=90^{\circ}\right)$

(b)

FIGURE 10: Measured and simulated radiation patterns of antennas II and III at 5 GHz. (a) Antenna II. (b) Antenna III.

the cross-polarized fields by more than $25 \mathrm{~dB}$. The radiation patterns were also simulated at other frequencies and very stable results were obtained across the entire passband.

\section{Conclusion}

Two slot-fed MP antennas which consist of metallic patch cells have been investigated in this paper. Compared with metamaterial-based mushroom antenna, the proposed designs have advantages of simple configuration, ease of fabrication, compact size, and even wider bandwidth. A parametric study of the MP antennas has been done to examine the effects of various parameters, and two prototypes operating at $5 \mathrm{GHz}$ were designed and fabricated. The antennas have a low profile of $0.06 \lambda_{0}$, a wide impedance bandwidth of $\sim 32 \%$, and a medium average gain of $\sim 10 \mathrm{dBi}$.

\section{Conflicts of Interest}

The authors declare that there are no conflicts of interest regarding the publication of this paper.

\section{Acknowledgments}

This work is supported by the Foundation of Key Laboratory of Polarization Imaging Detection Technology in Anhui Province (2016-KFJJ-005).

\section{References}

[1] E. Chang, S. A. Long, and W. F. Richards, "An experimental investigation of electrically thick rectangular microstrip antennas," IEEE Transactions on Antennas and Propagation, vol. 34, no. 6, pp. 767-772, 1986. 
[2] K. F. Lee, K. M. Luk, K. F. Tong, S. M. Shum, T. Huynh, and R. Q. Lee, "Experimental and simulation studies of the coaxially fed U-slot rectangular patch antenna," IEE Proceedings-Microwaves, Antennas and Propagation, vol. 144, no. 5, pp. 354-358, 1997.

[3] J. A. Ansari and B. Ram, "Analysis of broad band U-slot microstrip patch antenna," Microwave and Optical Technology Letters, vol. 50, no. 4, pp. 1069-1073, 2008.

[4] K. M. Luk, C. L. Mak, Y. L. Chow, and K. F. Lee, "Broadband microstrip patch antenna," Electronics Letters, vol. 34, no. 15, pp. 1442-1443, 1998.

[5] Y.-X. Guo, C.-L. Mak, K.-M. Luk, and K.-F. Lee, "Analysis and design of L-probe proximity fed-patch antennas," IEEE Transactions on Antennas and Propagation, vol. 49, no. 2, pp. 145-149, 2001.

[6] D. Sun and L. You, "A broadband impedance matching method for proximity-coupled microstrip antenna," IEEE Transactions on Antennas and Propagation, vol. 58, no. 4, pp. 1392-1397, 2010.

[7] F. Croq and A. Papiernik, "Stacked slot-coupled printed antenna," IEEE Microwave and Guided Wave Letters, vol. 1, no. 10, pp. 288-290, 1991.

[8] W. C. Yang, H. Wang, W. Q. Che, and J. J. Wang, "A wideband and high-gain edge-fed patch antenna and array using artificial magnetic conductor structures," IEEE Antennas and Wireless Propagation Letters, vol. 12, pp. 769-772, 2013.

[9] E. S. R. Montalvão, A. C. P. S. Montalvão, A. L. P. S. Campos, and A. Gomes Neto, "A new model of metasurface used for linear-tocircular polarization conversion in antenna array," Microwave and Optical Technology Letters, vol. 58, no. 4, pp. 861-864, 2016.

[10] H. L. Zhu, X. H. Liu, S. W. Cheung, and T. I. Yuk, "Frequencyreconfigurable antenna using metasurface," IEEE Transactions on Antennas and Propagation, vol. 62, no. 1, pp. 80-85, 2014.

[11] H. Zhu, S. W. Cheung, and T. I. P. Yuk, "Enhancing antenna boresight gain using a small metasurface lens: reduction in halfpower beamwidth," IEEE Antennas and Propagation Magazine, vol. 58, no. 1, pp. 35-44, 2016.

[12] Y. Dong and T. Itoh, "Metamaterial-inspired broadband mushroom antenna," in Proceedings of the IEEE International Symposium Antennas and Propagation and CNC-USNC/URSI Radio Science Meeting, pp. 1-4, Toronto, Canada, July 2010.

[13] W. Liu, Z. N. Chen, and X. Qing, "Metamaterial-based lowprofile broadband mushroom antenna," IEEE Transactions on Antennas and Propagation, vol. 62, no. 3, pp. 1165-1172, 2014.

[14] E. O. Hammerstad, "Equations for microstrip circuit design," in Proceedings of the 5th European Microwave Conference, pp. 268272, Hamburg, Germany, September 1975.

[15] G. Kumar and K. C. Gupta, "Broad-band microstrip antennas using additional resonators gap-coupled to the radiating edges," IEEE Transactions on Antennas and Propagation, vol. 32, no. 12, pp. 1375-1379, 1984.

[16] G. Kumar and K. P. Ray, Broadband Microstrip Antennas, Artech House, Inc, Norwood, Mass, USA, 2003.

[17] D. M. Pozar, Microwave Enginerring, John Wiley \& Sons, 4th edition, 2012. 


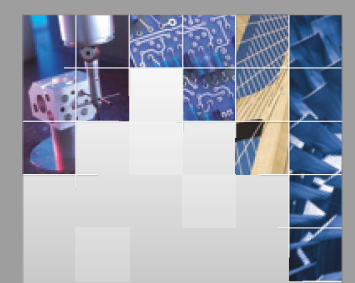

\section{Enfincering}
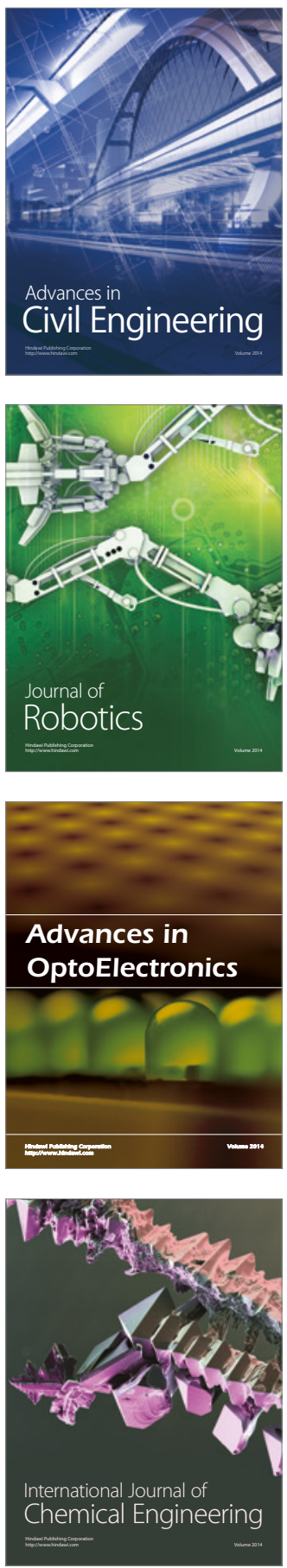

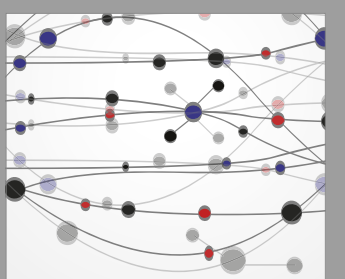

The Scientific World Journal

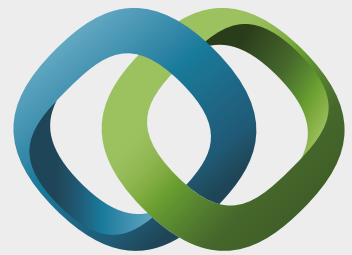

\section{Hindawi}

Submit your manuscripts at

https://www.hindawi.com
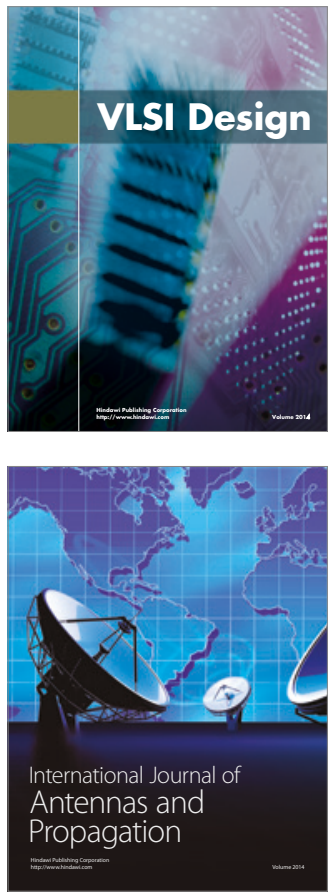

\section{Rotating}

Machinery
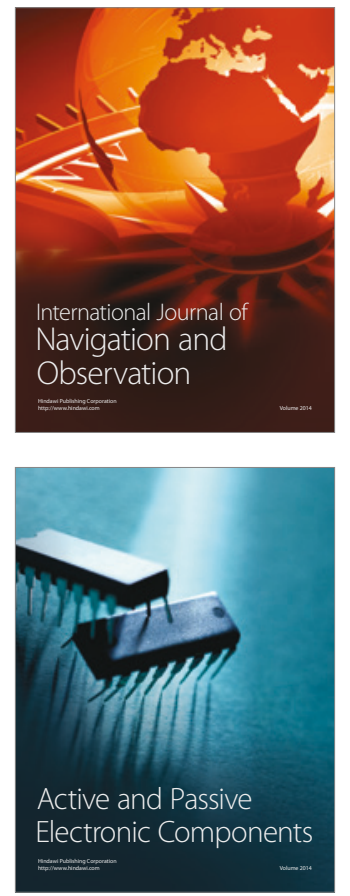
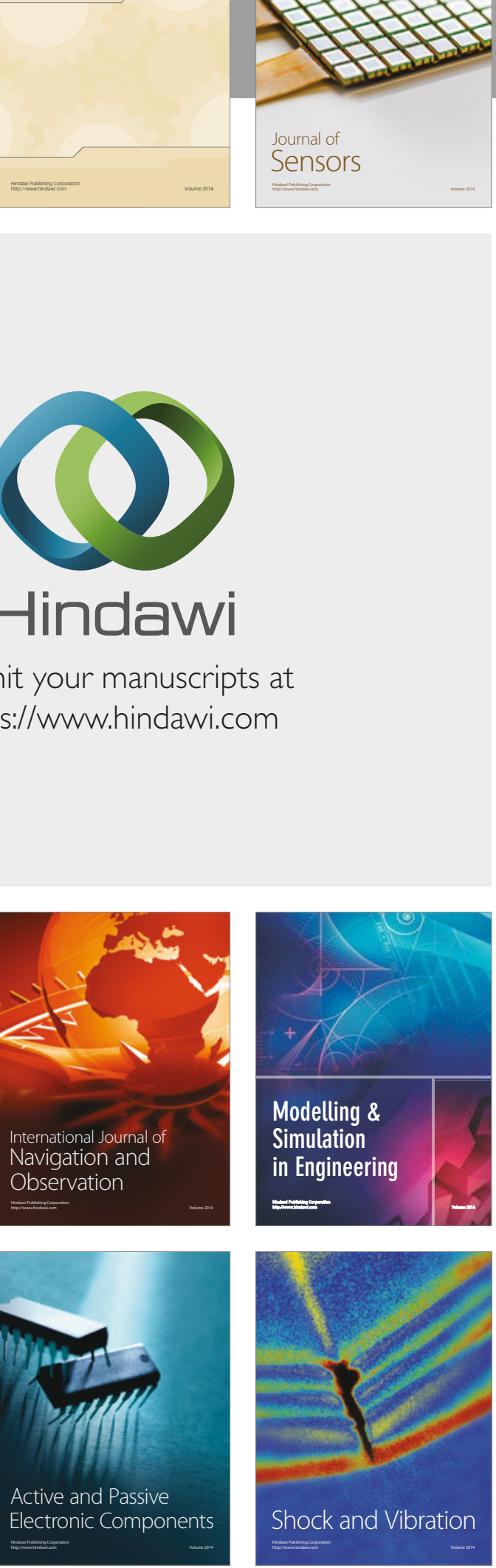
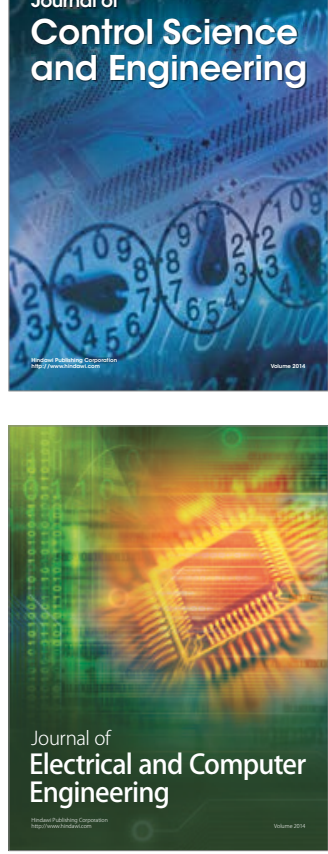

Distributed

Journal of

Control Science

and Engineering
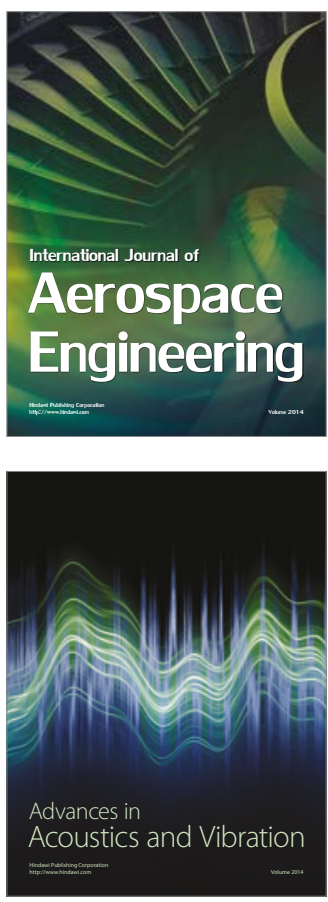

Sensor Networks 